\title{
Isolamento de microrganismos de interesse biotecnológico oriundos de áreas contaminadas com agroquímico.
}

\author{
Isolation of microorganisms of biotechnological interest from areas contaminated with \\ agrochemicals.
}

\author{
Mariana Santos Costa ${ }^{1}$, Thalison Rômulo Rocha Araújoㅇ, Ábia de Jesus Martins ${ }^{1}$, Queren \\ Hapuque Sousa da Silva ${ }^{1}$, Celso Henrique Costa $^{2}$, Rita de Cássia Mendonça de Miranda ${ }^{3}$
}

\begin{abstract}
Resumo: Introdução: O uso dos agroquímicos hoje tem causado dúvidas sobre a baixa ou inexistente patogenicidade nos microorganismos de solo, visto que, esses químicos, quando usados incorretamente, podem causar, alterações nesses microorganismos, os tornando mais resistentes gerando, consequentemente problemas, principalmente aos trabalhadores em contato, e aos consumidores finais do produto o qual esta sendo cultivado. Objetivo: Isolar e identificar os microorganismos encontrados no solo acometido pelo agroquímico para tentar identificar presença de patógenos. Materiais e métodos: Os métodos abordados foram simples, usando meio de cultura e diluição seriada das amostras, que foram os solos de uma horta situada no bairro J. Lima, em São José de Ribamar. Foram feitos o isolamento e identificação durante dois períodos, um seco e um chuvoso, e após o isolamento, a identificação foi realizada através de visualização da morfologia, no caso dos fungos, e a partir da coloração de Gram, no caso das bactérias. Resultados: Observando as colônias formadas e após identificar os microrganismos, notou-se a presença de fungos patógenos como principalmente a espécie Coccidioide $s p$., e bactérias cocos e bastonetes gram positivo e negativo, que podem também gerar sensibilidade ao usuário do alimento e principalmente ao trabalhador, partindo de que geralmente os químicos não são usados corretamente e também não há o uso dos equipamentos de proteção. Conclusão: De acordo com os resultados obtidos, e analisando a presença de microrganismos patogênicos no solo avaliado, percebemos que os microrganismos de solo podem, também gerar malefícios a sociedade, a partir do uso indevido dos agroquímicos.
\end{abstract}

Palavras-chave: Solo, Microrganismo, Isolamento.

\begin{abstract}
The use of agrochemicals today has caused doubts about the low or non-existent pathogenicity of soil microorganisms, since these chemicals, when used improperly, can cause alterations in these microorganisms, making them more resistant and, consequently, Contact, and final consumers of the product being grown. Objective: To isolate and identify the microorganisms found in soil affected by the agrochemical to try to identify pathogens. Materials and methods: The methods studied were simple, using culture medium and serial dilution of the samples, which were the soils of a vegetable garden located in the J. Lima neighborhood, in São José de Ribamar. Isolation and identification were done during two periods, one dry and one rainy, and after isolation, the identification was made through visualization of the morphology in the case of fungi, and from Gram staining in the case of bacteria. Results: The presence of pathogenic fungi, such as Coccidioide sp., And coccus bacteria and gram positive and negative rods, which may also generate sensitivity to the user of the food, Worker, starting from which generally the chemicals are not used correctly and also there is the use of protective equipment. Conclusion: According to the results obtained, and analyzing the presence of pathogenic microorganisms in the evaluated soil, we noticed that soil microorganisms can also generate harm to society, due to the improper use of agrochemicals.
\end{abstract}

Keywords: Soil, microrganisms, isolation.

1 - Graduação em Biomedicina - Universidade Ceuma

2 - Mestrando em Meio Ambiente - Universidade Ceuma

3 - Docente Doutora do Mestrado em Meio Ambiente da Universidade Ceuma

Rev. Investig, Bioméd. São Luís, 9:17-23, 2017 
Introdução

O uso de agroquímicos tem sido um fator importante para o trabalho agrícola no Brasil, devido suas funções acerca da proteção de determinadas vegetações. Porém, é de extrema importância 0 impacto causado por eles sobre o meio ambiente e a saúde humana.

A principal função desses compostos é inibir o crescimento de patógenos frequentes na agricultura já que de um modo geral possuem estruturas químicas e moleculares semelhantes a classes de antimicrobianos usados na clínica. Estes compostos possuem similaridade estrutural com azólicos clínicos e alguns passaram a ser proibido no Brasil pela ANVISA, motivado principalmente pela elevada toxicidade do produto ${ }^{1,2,3}$.

O solo é formado pela alteração da rocha-mãe, provocada pela interação de processos de natureza física, química e biológica que levam a degradação dessa rocha ${ }^{4}$

Dentro do enfoque ambiental e sanitário, a definição adotada pela Comunidade Europeia afirma que: $O$ solo é o principal suporte para a vida e o bem-estar, constituindo-se em um recurso natural vital e limitado, embora facilmente destrutível ${ }^{4}$.

Por tradição, o solo tem sido utilizado como receptor de substâncias resultantes das atividades humanas, principalmente para a disposição final de resíduo. A Revolução Industrial introduziu os processos de transformação em grande escala com emprego de tecnologia, foi um marco não apenas na mudança das atividades humanas, como também na ocupação e uso do solo. O modelo de desenvolvimento adotado pela economia moderna, baseado num crescente consumo de bens e serviços, impõe o desenvolvimento continuo de novos produtos, que demanda um uso intensivo dos recursos e insumos e geração cada vez maior de resíduos das atividades humanas, sejam industriais, agrícolas ou domésticas, provocando a liberação descontrolada de poluentes para o ambiente e sua conseqüente acumulação no solo tem aumentado significativamente a cada $\mathrm{dia}^{4}$.

O solo uma vez contaminado por esses resíduos trará consequências ambientais e sanitárias que, consequentemente, poderá ocorrer problemas econômico, sociais e políticos que poderão limitar ou até inviabilizar seu uso posterior. Essa contaminação do solo afeta direta e/ou indiretamente os microrganismos que vivem nesse meio, os mesmos são essenciais para armazenamento de água, decomposição de resíduos orgânicos, reciclagem de nutrientes, sequestro e desintoxicação de substâncias tóxicas ${ }^{5}$, e em alguns casos participam da fotossíntese. Assim a preocupação com a preservação, proteção, controle e recuperação do solo têm sido ampliada nas últimas três décadas, ocasião em que eventos de áreas contaminadas passaram a ser detectados ${ }^{4}$. Sendo assim, os microrganismos do solo, podem ser utilizados como indicador para medir os impactos sobre o solo ${ }^{6}$, sendo ainda, capazes de refletir mudanças sutis nas propriedades do solo ${ }^{7}$.

Em vista disso, faz-se necessário o estudo da microbiota do solo em locais contaminados, podendo ser uma maneira de provar que o contaminante pode causar sérios problemas a população. Nesse sentido, o presente trabalho visa quantificar e analisar fenotipicamente microorganismos isolados de solo contaminado por agroquímico utilizado na agricultura de hortaliça. 


\section{Material e Método}

Coleta: Foram realizadas duas coletas obedecendo um período de sazonalidade seco (janeiro) e chuvoso (abril) de solo impactado com agroquímico da classe dos organofosforado. Esta etapa foi realizada em uma propriedade de agricultores familiar que cultiva hortaliças localizada no município de são José de Ribamar, no bairro J. Lima.

Foram coletadas 10 amostras de solo separadas de forma equidistantes de um único canteiro da mesma horta. A distância entre as amostras foi de 3 metros uma da outra.

Após a coleta, as amostras foram armazenadas em sacos hermeticamente vedados e acondicionados sob refrigeração para posterior isolamento dos microrganismos.

Isolamento: para o isolamento dos microrganismos foi elaborada uma amostra composta do solo e utilizada a técnica de diluição seriada de acordo com a metodologia preconizada por Clark $^{8}$. Para isso diluiu-se $10 \mathrm{~g}$ da amostra composta do solo em $90 \mathrm{~mL}$ de solução salina. A partir desta solução, foram realizadas as diluições posteriores $\left(10^{-1}\right.$ ate $\left.10^{-4}\right)$ em tubos de ensaio contendo $0,5 \mathrm{~mL}$ das amostras e $4,5 \mathrm{~mL}$ de solução salina. As diluições $10^{-2}, \quad 10^{-3}$ e $10^{-4}$ foram plaqueadas através da técnica de spread plate nos meios de cultivo Muller Hinton Ágar e Sabouraud Dextrose Agar. Após inoculadas, as amostras foram incubadas a $30^{\circ} \mathrm{C}$ até o aparecimento das colônias.

Purificação das colônias: após o crescimento das colônias nos meios de cultivo, essas foram contada e posteriormente transferidas separada mente para placas de Petri contendo o mesmo meio de isolamento. Com o objetivo de se obter culturas puras foi utilizada a técnica repicagem por esgotamento. As placas foram incubadas a $30^{\circ} \mathrm{C}$ por até 72 horas.

Identificação: após obtenção das colônias isoladas e purificadas, as mesmas foram transferidas para tubos de ensaio contendo o mesmo meio do isolamento e deu-se início a identificação. Para as bactérias foi realizada a técnica de coloração de Gram onde foi possível dividir em Gram positiva e Gram negativa de acordo com a coloração tintorial da parede celular. Além disso por esta mesma técnica é possível observar morfologia e arranjo bacteriano. Para identificação dos fungos filamentosos se utilizou a técnica de microcultivo, as culturas crescem em forma de tapete na placa de Petri com formação de micélio aéreo para observação microscópica da conformação dos esporos dos fungos.

\section{Resultados}

Após o período de incubação das placas de Petri, contendo meio de cultura usados no isolamento pode-se observar o aparecimento das colônias. Após a contagem, constatou-se que a quantidade de microrganismos no período chuvoso é maior que no período seco, como se pode visualizar na Figura 1 e 2, todavia quando se faz a observação macro e microscópica se observa uma diversidade microbiana maior em período seco. 


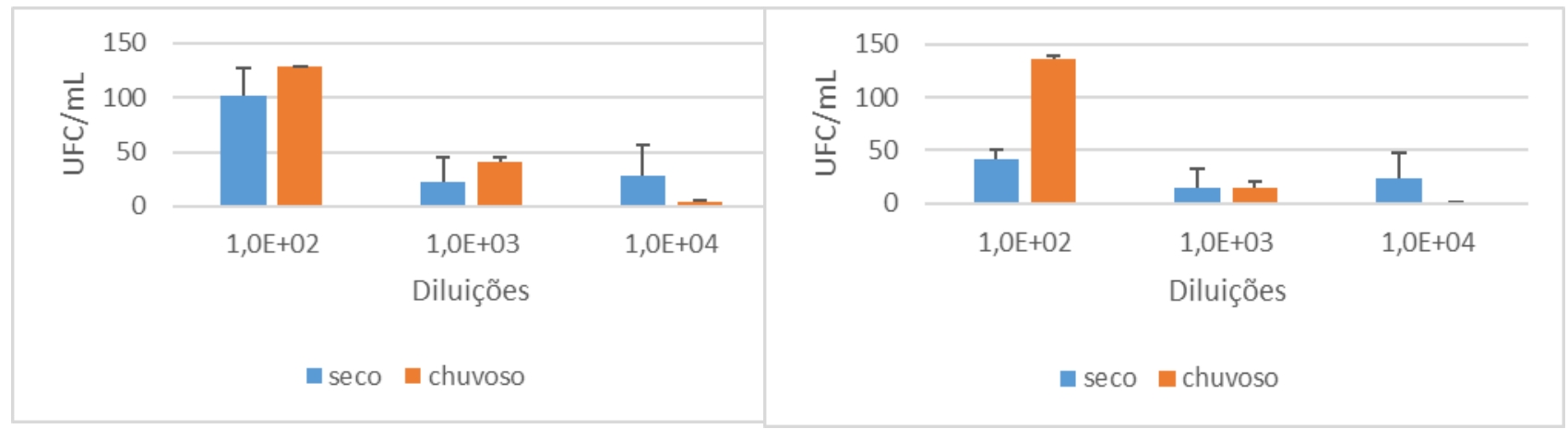

Figura 1 - isolamento de microrganismos no período seco e chuvoso no meio de cultura Müller Hinton Ágar.

Figura 2 - isolamento de microrganismos no período seco e chuvoso no meio de cultura Sabouraud Dextrose Ágar.

O quantitativo microbiano maior em período chuvoso, se deve, a umidade do solo está maior, possibilitando a prevalência de um grupo microbiano. Uma outra observação interessante é a prevalência em ambos os períodos do grupo dos fungos, demonstrando que estes estão em maior número no solo contaminado com agroquímico. Logo após a observação macroscópica, observou-se três grupos distintos de colônias. No meio de cultivo Müller Hinton Ágar o crescimento foi mais uniforme, as colônias se mostraram mais uniformes em relação ao tamanho, os bordos liso ou em forma de ondas, sugerindo colônias formadas por bactérias do gênero Bacillus. No meio de cultivo Sabouraud Dextrose Ágar observou-se colônias de aspecto algodonoso, sugerindo a formação de micélio aéreo de fungos filamentosos e colônias leitosas opacas e com bordas lisas bem delimitadas características de leveduras. Neste meio também se pode observar a formação de halo de antibiose como pode ser visualizado na Figura 3.

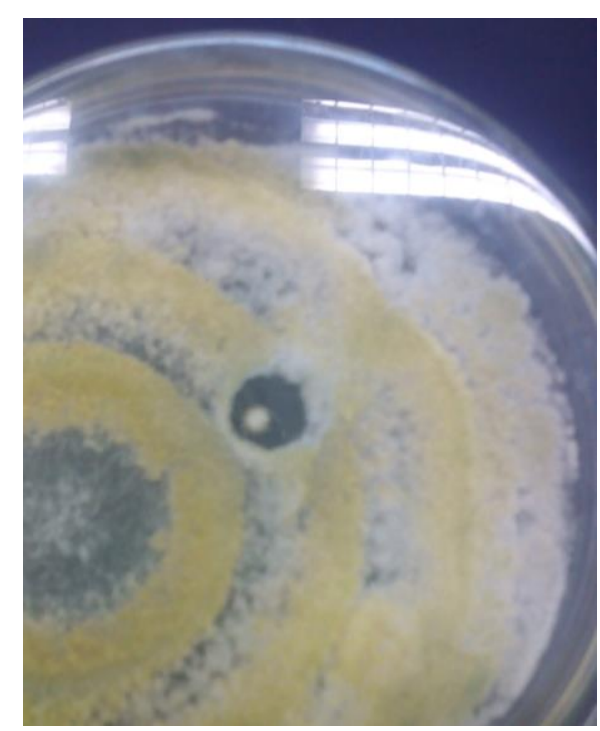

Figura 3 - aspecto macromorfológico das colônias no meio de cultivo Sabouraud Dextrose Ágar. 
Após a contagem e purificação das colônias deu-se início a identificação dos microrganismos, foi realizado o teste de coloração de Gram para as bactérias e o microcultivo em lâmina para os fungos e o que se observou foi que dos microrganismos isolados $29 \%$ eram Bastonetes $\mathrm{G}^{+}, 13 \%$ Bastonetes $\mathrm{G}^{-}, 29 \%$ Cocos $\mathrm{G}^{+}, 16 \%$ de Fungos Filamentosos e $13 \%$ de Leveduras como pode ser visualizado na Figura 4.

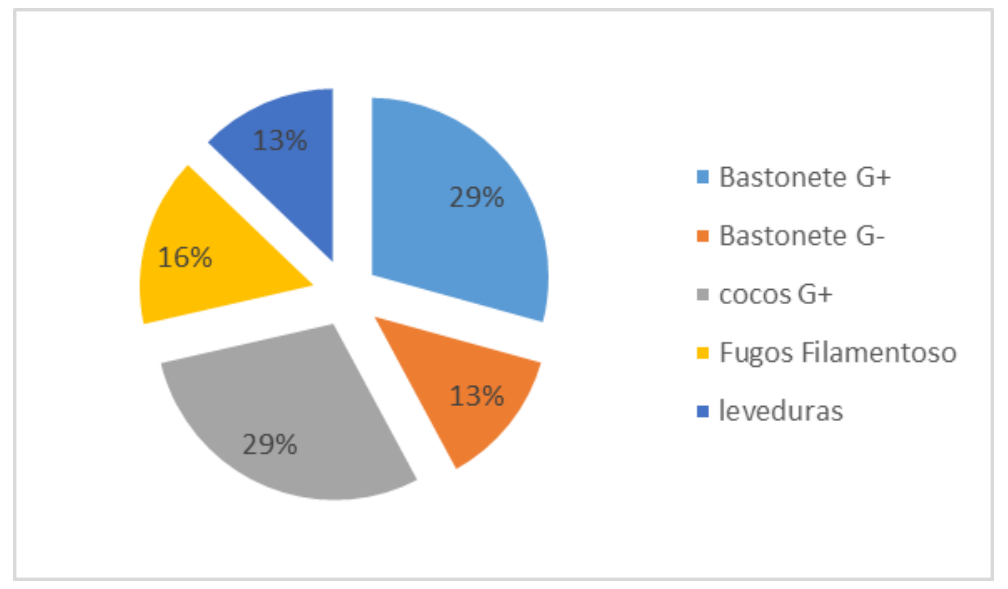

Figura 4 - percentual de microrganismos isolados

Após a coloração tintorial da parede celular (coloração de Gram) pode se observar a duas formas bacterianas distintas, cocos e bastonetes de ambas as colorações, positiva e negativa. Além disso, foi possível observar alguns arranjos bacteriano como cacho, duas células juntas e uma fileira de células arranjadas.

Com exceção do grupo das leveduras, pode-se observar diversidade entre os microrganismos, tanto nos aspectos macroscópicos quanto nos microscópicos. A prevalência de bactérias $\mathrm{G}^{+}$pode ser explicada pela habilidade desse grupo bacteriano de resistir a ambientes inóspitos, e também por abrigar o grupo dos Actinomicetales, que são bactérias Gram Positivas filamentososas, diferenciadas das demais Eubactérias. Dentre os fungos filamentosos foram identificados quatro gêneros diferente: três Penicillium spp, 01 Aspergillus sp., 01 Trichoderma sp e um Coccidioide sp., fungo patogênico, comum em solo causador de meningite como pode ser visualizado na Tabela 1. Nas observações micromorfológica dos fungos pode-se observar a conformação dos esporos nas extremidades das hifas, além disso pode-se observar se tratavam de hifas hialinas ou septadas corroborando com a identificação dos fungos. Nas figuras $5 \mathrm{~A}, 5 \mathrm{~B}$ e $5 \mathrm{C}$ se pode visualizar a micromorfologia dos fungos Aspergillus, sp. Penicillium sp e Coccidioide sp. respectivamentes. As características macromorfológicas avaliadas consistiram no tamanho da colônia, características dos bordos, textura, relevo e pigmentação. Já as análises micromorfológicas foram realizadas pela técnica de microcultivo em ágar-batata, visando identificar as estruturas vegetativas e especialmente as estruturas reprodutivas específicas dos gêneros de fungos filamentosos como pode ser visualizada na figura 5 . 

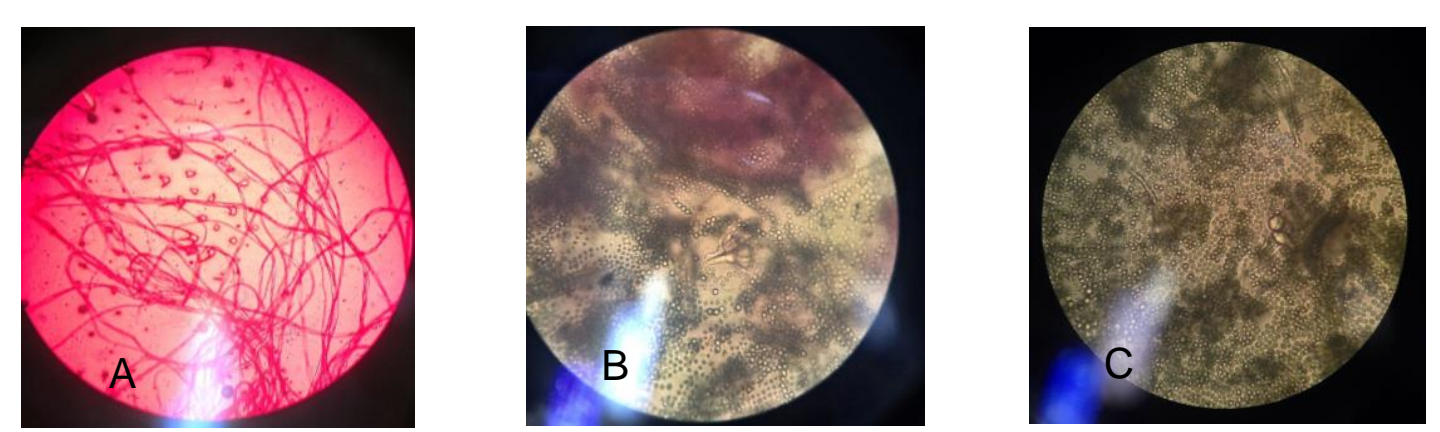

Figura 5 - características micromorfológicas dos fungos filamentsoso isolados de solo.

\section{Discussão}

Com os resultados obtidos pode-
se observar uma quantidade
microbiana elevada dos três grupos
isolados. Corroborando com este
trabalho pode ser observado no
trabalho de Santos \& Batista9. Os
autores isolando microorganismos de
solo contaminado com esgoto
doméstico nos períodos secos e
chuvosos encontraram um quantitativo
de UFC/mL semelhante ao encontrado
neste trabalho. Entretanto, quando ao
estudarem a influência da
sazonalidade na quantidade e
diversidade microbiana os resultados
encontrados pelas autoras foram
contrários aos nossos, quando as
mesmas obtiveram um maior
quantitativo microbiano no período
seco. Quanto a influência da
sazonalidade no isolamento dos
microrganismos resultados semelhan-
tes ao desse trabalho foram
encontrados por Silva et al el e
Rodrigues et al onde os maiores
resultados da população bacteriana
foram identificados no período
chuvoso. Uma outra observação
relatada neste trabalho foi a
identificação de gêneros de fungos
diferentes, neste sentido, corroborando

com o trabalho Andrade et $\mathrm{al}^{12}$, isolou fungos de solo contaminado em uma área próximo a mata Atlântica e constatou a presença predominante do gênero Cunnigamella sp.

\section{Conclusão}

De acordo com os resultados obtidos pode-se observar que mesmo com o solo contaminado com agroquímico, ainda se observa uma ampla quantidade e diversidade microbiana, sendo este fato, preocupante devido a possibilidades desses organismos estarem resistentes a compostos como antibióticos. Todavia, para sobreviver ao ambiente inóspito, é importante que essa microbiota tenha desenvolvido um aparato enzimático específico que pode ser interessante para do ponto de vista biotecnológico. 


\section{Referências}

1. Choedary A, Kathuria $\mathrm{S}, \mathrm{Xu} \mathrm{J}$, Meis JF Emergence of Azole-Resistant Aspergillus fumigatus Strains due to Agricultural Azole Use Creates an Increasing Threat to Human Health. PLoS Pathog 9 (10), 2013.

2. Farias-Ramos et al. Development of crossresistance by Aspergillus fumigatus to clinical azoles following exposure to prochloraz, an agricultural azole. BMC Microbiology 14: 155; 2014.

3. Philippi JR. A. et al. Educação ambiental e sustentabilidade, Barueri: Manole, 2005.

4. Lima, A. L de; Uso de EDTA e de feijão-deporco micorrizado em solo contaminado por metais pesados e boro - Campinas, Brasil, 2008 f. 80. Dissertação (Conclusão de mestrado em Agricultura Tropical e Subtropical Área de Concentração em Gestão de Recursos Agroambientais) Instituto agronômico curso de pós graduação em agricultura tropical e subtropical. Campinas, São Paulo, 2008. Disponivel em: http://www.iac.sp.gov.br/PoslAC/pdf/pb1211 306.pdf. Acesso em: ago, 2017.

5. Coimbra, J.L.M. Denardin, R. B. N. Gatiboni, L.C. Wildner, L.P, Modificações na fauna edáfica durante a decomposição da palhada de centeio e aveia preta, em sistema plantio direto. Biotemas., Lages. v. 22, n. 2, p. 4553, 2009.

6. Junior, F. B. R. Mendes, I. C. Teixeira, K. R. S. Reis, V. M. Uso de ferramentas moleculares em estudos da diversidade de microrganismos do solo. Embrapa Empresa Brasileira de Pesquisa Agropecuária, 2002.

7. Clark, F.E. Agar-plate method for total microbial count. Pp. 1460-1466, 1965. In: C.A. Black; D.D. Evans; J.L. White; L.E. Ensminger; F.E. Clark \& R.C. Dinaver (eds.). Methods of soil analysis, Part 2. Chemical and microbiological properties. New York, Madson Inc., 1995

8. Santos, A. P. A; Batista, S. B. Isolamento e caracterização fenotípica de microorganismos isolados de solo poluído por resíduos sólidos do bairro carrapicho município de Várzea Grande - Mato Grosso. Connection Line, Várzea Grande, v. 12, p. 29-43, 2015. Silva, N. Característica do Cerrado, São Paulo: 15. fev. 2008. Disponível em http://pt.shvoong.com/exactsciences/agronomy-agriculture/1765522cerrado/. Acesso em: ago. 2017.

9. Rodrigues, H. B. Ruivo, M. L. Lôla, A. C. Mello, I. F. Moura, Q. L. Viana, R. S. Variabilidade quantitativa de populações microbiana observada em solo de floresta tropical úmida, associada às condições microclimáticas. Disponível em: http://www.cbmet2010.com/anais/artigos/76_ 91999.pdf. Acesso em: ago, 2017.

10. Andrade, M.V.R.F. , Deusdará, T.T. Scheidt, G.N., Chagas Jr, A.F., Isolamento, caracterização fenotípica e perfil de crescimento de cepas do fungo Cunninghamella sp. de solo do Sul do Tocantins, Brasil. 